\title{
Providing pharmacy services at cabin hospitals at the coronavirus epicenter in China
}

\author{
Long Meng ${ }^{1} \cdot$ Feng Qiu ${ }^{1} \cdot$ Shusen Sun ${ }^{2,3,4}$
}

Received: 17 March 2020 / Accepted: 23 March 2020 / Published online: 2 April 2020

(c) Springer Nature Switzerland AG 2020

\begin{abstract}
In the Chinese coronavirus epicenter, Wuhan, 16 cabin hospitals were built to admit patients with confirmed coronavirus infection (COVID-19). These cabin hospitals serve the role of effectively quarantine and treat mild cases of patients infected with COVID-19. Each cabin hospital has pharmacists to provide services and pharmaceutical care to patients. Pharmacists also provide assistance to cabin hospitals through remote internet platforms across China. In this commentary, we describe pharmacy services at cabin hospitals to share our experiences with the international pharmacy community.
\end{abstract}

Keywords Cabin hospital $\cdot$ China $\cdot$ COVID-19 $\cdot$ Pharmaceutical care $\cdot$ Pharmacists $\cdot$ Pharmacy service

\section{Impacts on practice}

- At coronavirus epicenters, cabin hospitals can be built to quarantine and treat mild cases of coronavirus infection.

- Pharmacists at cabin hospitals can be charged with establishing drug formularies, stocking formulary drugs, and providing clinical decision support for the appropriate use of formulary drugs.

- Multimedia educational materials and remote online pharmacy services may be considered to meet the unique needs of pharmacy services at cabin hospitals.

Feng Qiu

qiufeng.cn@outlook.com

$\triangle$ Shusen Sun

ssun@wne.edu

1 Department of Pharmacy, The First Affiliated Hospital of Chongqing Medical University, Chongqing 400016, China

2 Department of Pharmacy Practice, College of Pharmacy and Health Sciences, Western New England University, Springfield, MA 01119, USA

3 Department of Pharmacy, Xiangya Hospital, Central South University, Changsha 410008, Hunan, China

4 The Hunan Institute of Pharmacy Practice and Clinical Research, Changsha 410008, Hunan, China

\section{Introduction}

In December 2019, novel coronavirus (2019-nCoV)-infected pneumonia (COVID-19) occurred in Wuhan, China, and the city has rapidly become the epicenter of the disease. As of March 13, 2020, there are 80,991 confirmed COVID-19 cases in China, including 3180 deaths [1]. To contain the coronavirus in Wuhan, all patients with confirmed diagnosis of COVID-19 are required to be admitted to healthcare facilities. However, with the rapid increase of confirmed cases, healthcare facilities quickly ran out of hospital beds and could not admit new patients including patients who also needed medical attention. To effectively contain COVID19 at the epicenter, cabin hospitals were transformed from large space places such as convention and exhibition centers, gyms, factories, warehouses, etc., in the City of Wuhan. These hospitals can quickly admit and treat a large number of patients following established standard operational and organizational protocols. Cabin hospitals have three primary functions: (1) provide isolation to patients to block off the transmission caused by close contact with family members and the general public, (2) provide medical treatment to patients with mild diseases based on disease characteristics, and (3) monitor patient's condition closely and immediately transfer patients to designated hospitals for intensive care in the event patient's condition deteriorates.

As of March 10, all 16 cabin hospitals in Wuhan have been closed. These cabin hospitals have completed the treatment of 12,000 COVID-19 patients and have played an 
essential role in fighting the epidemic. One of the authors of this commentary, LM, worked at two cabin hospitals in Wuhan, China, from February 4 to March 10, 2020. At cabin hospitals, pharmacists usually work between 8 and $14 \mathrm{~h} \mathrm{a}$ day, 5-6 days per week. In this commentary, we would like to describe pharmacy services at cabin hospitals based on personal experiences to disseminate information to the international pharmacy community.

\section{Ensure the supply of medicines and resolve medication shortages}

At cabin hospitals, pharmacists are tasked to establish pharmacies from grounds up, including locating the ideal pharmacy location, procuring necessary equipment, compiling drug formulary, cataloging and stocking formulary drugs, and creating a medicinal dictionary for formulary drugs to be docked into the clinical decision support system (CDS) to provide prescribing support.

The following principles are used to create a standardized drug formulary at cabin hospitals: (1) oral dosage forms are preferred as patients being treated are of mild severity, and oral medications are more comfortable to administer while avoiding the risks of infections that parenteral injections may present, (2) a higher priority is given to medications recommended by the China National Health Commission guidelines, "Diagnosis and Treatment Guidelines for the New Coronavirus Infected Pneumonia" (the CNHC guidelines, currently in its seventh update) [2]. The CNHC guidelines recommend the use of antiviral drugs ( $\alpha$-interferon, lopinavir/ritonavir, ribavirin, chloroquine, umifenovir) and traditional Chinese medicines (TCMs) for the treatment of patients infected with COVID-19. When considering the number of drugs needed to be stocked, pharmacists should view each drug's treatment efficacy, safety, and route of administration. For example, $\alpha$-interferon is administered through aerosol inhalation requiring an atomizing device, and there is a risk of virus transmission by inhalation. Ribavirin is administered intravenously, and both lopinavir/ritonavir and chloroquine have more safety concerns [2], and (3) the drug formulary should include medications for the relief and treatment of the coronavirus, as well as mitigating the symptoms of the disease such as antipyretic analgesics, antibiotics, hepatoprotective drugs, medicines for the regulation of intestinal microorganisms, digestive medications, respiratory medications, and psycho-neurological medications. Medications for patients with chronic diseases such as hypertension, heart disease, and asthma should be stocked to continue their treatment while in isolation, as well as resuscitation and emergency drugs. In general, the drug formulary contains approximately 100 medications for stocking (Table 1).
Given the urgency of the operation, not all medications are delivered to the pharmacy on time. Pharmacists are responsible for resolving drug shortages in various ways, such as monitoring drug utilization in real-time, transferring drugs from other pharmacies, and allowing patients to selfpurchase drugs for their personal use.

\section{Ensure pharmacy operation efficiency through adjusting pharmacist workflow}

Generally, there are not enough pharmacists working at cabin hospitals. For example, at the two hospitals the author (LM) worked, there were only three pharmacists providing care for almost 1000 patients. To meet the demand for pharmacy services, pharmacists must adjust workflow to optimize operational efficiency. The following is a discussion of the measures that may be considered: (1) preparing and maintaining drug par levels for each hospital ward. Ensure drugs are replenished daily based on consumption and the demand of the ward, this will effectively reduce the frequency of pharmacy dispensing and avoid unnecessary repeated labor, and (2) change the mode of drug delivery to prevent infection and further control the spread of the disease. Personnel should not be allowed to enter and leave the ward (polluted area) at will, and this may result in the inability of drugs being delivered to the ward on time. To this end, pharmacists provide drugs to the outside of the buffer zone, and coordinate hospital and ward staff to transfer medications inside wards.

\section{Provide direct pharmaceutical care at cabin hospitals}

At cabin hospitals, most patients have mild or suppressed symptoms following admission. Clinical symptoms patients mostly present with are fever, dry cough, and fatigue. Some patients also show nasal congestion, runny nose, sore throat, myalgia, and diarrhea. Except for a small percentage of patients requiring no treatment, most patients received antivirals and drugs for symptomatic relief. Pharmacists typically provide the following pharmaceutical care: (1) educating patients on medications taken at the hospital and upon discharge (focusing on drug administration and precautions), (2) providing necessary drug information to physicians especially concerning drugs that general practitioners are not familiar with a focus on off-label drug use, and interactions between TCMs and western medicines, and (3) performing medication reconciliation to ensure the safe transition of care. Although cabin hospitals treat patients with mild cases, some patients may also have chronic diseases such as cardiovascular and cerebrovascular diseases and diabetes. Patients' chronic medications may have to be adjusted as the cabin hospital drug formulary is relatively limited. 
Table 1 Drug formulary at cabin hospitals in Wuhan, China

\begin{tabular}{|c|c|c|c|c|c|}
\hline Therapeutic category & Drug name & Therapeutic category & Drug name & Therapeutic category & Drug name \\
\hline \multirow[t]{7}{*}{ Antivirals } & Ribavirin $^{\mathrm{a}, \mathrm{b}}$ & Allergies & Loratadine $^{\mathrm{a}}$ & Emergency drugs & Adrenaline $^{\mathrm{b}}$ \\
\hline & Interferon- $\alpha^{\mathrm{b}, \mathrm{c}}$ & & Promethazine $^{\mathrm{b}}$ & & Anisodamine $^{\mathrm{b}}$ \\
\hline & Lopinavir/ritonavir ${ }^{\mathrm{a}}$ & Hepatoprotective drugs & $\begin{array}{l}\text { Diammonium } \\
\text { glycyrrhizinate }^{\mathrm{a}}\end{array}$ & & Atropine $^{\mathrm{b}}$ \\
\hline & Arbidol $^{\mathrm{a}}$ & & $\begin{array}{l}\text { Compound } \\
\text { glycyrrhizin }^{\mathrm{b}}\end{array}$ & & Deslanoside $^{\mathrm{b}}$ \\
\hline & Chloroquine phosphate ${ }^{\mathrm{a}}$ & Glucocorticoids & Dexamethasone $^{\mathrm{a}}$ & & Dopamine $^{\mathrm{b}}$ \\
\hline & Hydroxychloroquine $^{\mathrm{a}}$ & & Prednisone acetate ${ }^{\mathrm{a}}$ & & Furosemide $^{\mathrm{b}}$ \\
\hline & Oseltamivir $^{\mathrm{a}}$ & & Methylprednisolone ${ }^{\mathrm{a}, \mathrm{b}}$ & & $\begin{array}{l}\text { Glucose injection } \\
(50 \%)^{\mathrm{b}}\end{array}$ \\
\hline \multirow[t]{6}{*}{ Anti-bacterials } & Amoxicillin $^{\mathrm{a}}$ & Cardiovascular drugs & Amlodipine $^{\mathrm{a}}$ & & Glyceryl trinitrate $^{\mathrm{b}}$ \\
\hline & Azithromycin $^{\mathrm{a}}$ & & Nifedipine $^{\mathrm{a}}$ & & Hydroxylamine $^{\mathrm{b}}$ \\
\hline & Cefaclor $^{\mathrm{a}}$ & & $\begin{array}{l}\text { Isosorbide } \\
\text { mononitrate }^{\mathrm{a}}\end{array}$ & & Isoprenaline $^{\mathrm{b}}$ \\
\hline & Cefidipine $^{\mathrm{a}}$ & & Irbesartan $^{\mathrm{a}}$ & & Lidocaine $^{\mathrm{b}}$ \\
\hline & Levofloxacin $^{a}$ & & Candesartan ${ }^{\mathrm{a}}$ & & Nikethamide \\
\hline & Moxifloxacin $^{a}$ & & Metoprolol $^{\mathrm{a}}$ & & Noradrenaline $^{\mathrm{b}}$ \\
\hline \multirow[t]{6}{*}{ Respiratory drugs } & Pentoverine $^{\mathrm{a}}$ & & Bisoprolol $^{\mathrm{a}}$ & & \\
\hline & $\begin{array}{l}\text { Compound methoxy- } \\
\text { phenamine capsules }\end{array}$ & & Clopidogrel $^{\mathrm{a}}$ & & \\
\hline & Acetylcysteine $^{\mathrm{a}}$ & & Aspirin $^{a}$ & & \\
\hline & Fudosteine $^{\mathrm{a}}$ & & Atorvastatin $^{\mathrm{a}}$ & & \\
\hline & Acetylcysteine $^{\mathrm{a}}$ & & Furosemide $^{\mathrm{a}}$ & & \\
\hline & Ambroxol $^{\mathrm{a}}$ & & Hydrochlorothiazide $^{\mathrm{a}}$ & & \\
\hline \multirow{4}{*}{$\begin{array}{l}\text { Non-steroidal antiin- } \\
\text { flammatory drugs }\end{array}$} & Diclofenac sodium ${ }^{\mathrm{a}}$ & Endocrinology drugs & Acarbose $^{\mathrm{a}}$ & & \\
\hline & Ibuprofen $^{\mathrm{a}}$ & & Glimepiride $^{\mathrm{a}}$ & & \\
\hline & Indometacin $^{\mathrm{a}}$ & & Gliclazide $^{\mathrm{a}}$ & & \\
\hline & Paracetamol $^{\mathrm{a}}$ & & Metformin $^{\mathrm{a}}$ & & \\
\hline \multirow[t]{9}{*}{ Gastrointestinal drugs } & Hydrotalcite $^{\mathrm{a}}$ & & Levothyroxine $^{\mathrm{a}}$ & & \\
\hline & Lansoprazole $^{\mathrm{a}}$ & $\begin{array}{l}\text { Neurologic and psychi- } \\
\text { atric drugs }\end{array}$ & Alprazolam ${ }^{\mathrm{a}}$ & & \\
\hline & Omeprazole $^{\mathrm{b}}$ & & Epalrestat $^{\mathrm{a}}$ & & \\
\hline & Domperidone $^{\mathrm{a}}$ & & Estazolam $^{\mathrm{a}}$ & & \\
\hline & $\begin{array}{l}\text { Montmorillonite } \\
\text { powder }^{\mathrm{a}}\end{array}$ & & Escitalopram $^{\mathrm{a}}$ & & \\
\hline & Lactulose $^{\mathrm{a}}$ & & Zopiclone $^{\mathrm{a}}$ & & \\
\hline & Glycerol enema & & Zolpidem $^{\mathrm{a}}$ & & \\
\hline & $\begin{array}{l}\text { Bacillus licheniformis } \\
\text { capsule }\end{array}$ & $\begin{array}{l}\text { Vitamin and electrolyte } \\
\text { drugs }\end{array}$ & Vitamin $C^{a}$ & & \\
\hline & $\begin{array}{l}\text { Live combined bifido- } \\
\text { bacterium, lactobacil- } \\
\text { lus and enterococcus } \\
\text { powder }^{\mathrm{a}}\end{array}$ & & Potassium chloride ${ }^{\mathrm{a}}$ & & \\
\hline
\end{tabular}

${ }^{\mathrm{a} O}$ Oral formulation

${ }^{\mathrm{b}}$ Injection formulation

${ }^{c}$ Interferon- $\alpha$ includes interferon- $\alpha 1 b$, interferon- $\alpha 2 a$ and interferon- $\alpha 2 b$

Pharmacists must also focus on particular patient populations such as the pregnant and elderly when care demand for pharmacists is high. In addition to routine pharmaceutical care, pharmacists should assist physicians in monitoring patients' mental health wellbeing as there is also a severe shortage of front-line physicians. Patients may develop 
anxiety and sleep disturbances during the hospital stay as being in isolation takes a toll on their mental health. These problems patients are faced with may also be a concern of being infected with the coronavirus or due to the side effects of medications.

\section{Deliver multi-media educational materials and remote pharmaceutical care to hospitalized patients}

Because of the infection control restrictions of pharmacists entering hospital wards and inadequate numbers of pharmacists working at each cabin hospital, pharmacists can deliver pharmaceutical care via multi-media educational materials and remote video/phone conversations to hospitalized patients. The pharmaceutical care activities mentioned above, can be provided to patients and physicians by pharmacists, regardless of their work locations, with the help of multi-media technology. Educational materials are created, targeting patients' medication needs at admission, during hospitalization, and upon discharge. The Union Hospital affiliated to Tongji Medical College of Huazhong University of Science and Technology launched the "Online Pharmaceutical Monitoring" service [3], and the Beijing Pharmacist Association launched the "Yunwen Medicine" service [4]. The "Yunwen Medicine" platform brings together a team of outstanding pharmacists in Beijing, China. Drug information questions from patients or pharmacists at cabin hospitals are uploaded to the cloud platform and are answered promptly. These two remote access platforms allow pharmacists to communicate with physicians and patients on a one-to-one basis to effectively and efficiently identify and resolve drugrelated problems.

\section{Conclusion}

On March 10, 2020, all cabin hospitals in Wuhan were closed with the control of the epidemic in the city. Pharmacists provided valuable pharmacy services, and pharmaceutical care at cabin hospitals. Through these services, pharmacists have presented their professional competence, dedication and responsibility to patients, other healthcare providers, and society.

Acknowledgements We gratefully acknowledge the dedication of the following pharmacists who worked at the cabin hospitals of Wuhan and their shared experiences: Yingsong Wei, Yong Yang, Jiangping Lian, Wei Liu, Yingxing Wang, Jianguo Xu, Yake Guo, Jianlong Ma, Zhongsheng Gu, Guoxin Huang, Zhijun Cheng, Di Su. Authors would like to thank Joseph P Polidoro, Doctor of Pharmacy Candidate at Western New England University College of Pharmacy and Health Sciences, for proof-reading this manuscript.

Funding None.

Conflicts of interest All authors declare that they have no conflicts of interest.

\section{References}

1. WHO Coronavirus Disease 2019 (COVID-19) Situation report-53. https://www.who.int/docs/default-source/coronaviruse/situationreports/20200313-sitrep-53-covid-19.pdf?sfvrsn=adb3f72_2. Accessed 13 March 2020.

2. China National Health Commission. Diagnosis and Treatment Guidelines for the New Coronavirus Infected Pneumonia (seventh update). http://www.nhc.gov.cn/yzygj/s7653p/202003/46c92 94a7dfe4cef80dc7f5912eb1989.shtml. Accessed 20 March 2020.

3. Gong W, Wu S, Wu T, Zeng F, Shen C, Han Y, et al. Pharmaceutical care for coronavirus disease (CVID-19) in square cabin hospital. Herald of Medicine. http://kns.cnki.net/kcms/detai 1/42.1293.R.20200309.1950.004.html. Accessed 14 March 2020.

4. Pharmacy Department Supports Hubei Cabin Hospitals via Internet + Pharmacy. http://www.zxyjh.com.cn/news/803.html. Accessed 14 March 2020.

Publisher's Note Springer Nature remains neutral with regard to jurisdictional claims in published maps and institutional affiliations. 